\title{
Patient Awareness of Cost of Treatment at a Government Sponsored Hospital in India
}

\section{Ritesh $^{1}$, Harsh Mohinder Singh ${ }^{2}$ and Bikram Jit Singh ${ }^{3}$}

${ }^{1}$ Department of Pediatrics, ITFH Tajikistan

${ }^{2}$ Base Hospital Barrackpore, 24 North Parganas, West Bengal, India

${ }^{3}$ Department Mechanical Engineering, Maharishi Markandeshwar, Deemed to be University, Mullana, India

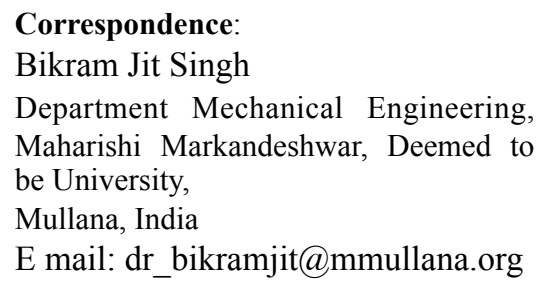

E mail: dr bikramjit@mmullana.org

DOI:10.3126/jnps.v39i3.28614

Submitted on: $2020-04-20$

Accepted on: 2020-05-06

Acknowledgements: None

Funding: Nil

Conflict of Interest: None declared

Permission from IRB: Yes

To cite this article: Ritesh, Singh HM, Singh BJ. Patient awareness of cost of treatment at a government sponsored hospital. J Nepal Paediatr Soc. 2019;39(3):147-54.

\begin{abstract}
Introduction: To evaluate the awareness amongst the beneficiary about the costs of medical services in a hospital which provides all services at no cost and also to analyse whether education level of the beneficiary client, number of days stayed in hospital and their prior exposure of being treated on payment in other hospital has some bearing on cost estimation by the participants.
\end{abstract}

Method: It was a cross sectional questionnaire based survey study. A total of 130 beneficiary clientele of a government hospital were interviewed. Two sample ' $t$ ' test and ANOVA were used for statistical analysis. Multivariate regression analysis was used to study effect of more than one independent variable on cost estimation. Scatter plot and box plots were used to study standard deviation.

Results: It revealed poor awareness of people in cost estimation of medical expenses. A significant ' $p$ ' value of $<0.05$ was observed with respect to length of stay $(p=0.003)$, treatment modality $(\mathrm{p}=0.000)$ and multivariate variable (treatment technique along with exposure to treatment in paid hospital, $\mathrm{p}=$ $0.008)$.

Conclusion: The beneficiary clientele in a hospital with free treatment generally not aware about the exuberant costs of treatment born by the state.

Keywords: health care expenses; treatment cost; treatment cost awareness; treatment cost estimation 


\section{INTRODUCTION}

With the advent of modern technology a large number of patients are reaping the benefits of advance health services; albeit at a cost of high health care expenditure. ${ }^{1}$ Many institutions provide treatment to its clientele at low or no cost and the expenses are borne by the institution. ${ }^{2}$ Alexander et al found in their study that both the physician and patients desire to discuss about the cost of treatment in the hospital. But such communication does not take place because of lack of cost awareness. ${ }^{3}$ The comprehensive cost of treatment consists of direct and indirect cost and both have subheads and components. ${ }^{4}$ Treatment expenditures are also calculated as costs from fixed assets and recurring expenditures. Fixed or capital cost consists of cost of the building, equipment and furniture required in hospital whereas recurring expenditure consists of staff salaries, drugs and consumables, laundry, payments for telephone, electricity, referral cost and other miscellaneous heads. ${ }^{5}$ Our hospital provides free medical services to our dependent clientele from inception of their service till retirement. Medical benefits are given to the employees as well as their family members. In this scenario, the patient remains unaware about the expenditure incurred on them by the institution. To the best of our knowledge, no study has been carried out in Indian government sponsored hospital to find the treatment cost awareness among the beneficiary clientele.

The primary objective of the study was to evaluate the level of awareness about the health care expenses incurred on a pregnant woman admitted for pregnancy completion along with their newborn babies in a hospital which provides all health services at no cost. Secondary objective of this study was to find out whether the education level of the client, number of days stayed in hospital, mode of delivery and their prior exposure of being treated on payment in other hospital have some bearing on expenditure estimation by the participants.

\section{METHODS}

It was a cross sectional study, conducted in a tertiary care level government sponsored hospital in India from 1 March 2015 through 1 March 2017. The study was approved by the hospital ethics committee and informed consent for participation was obtained from parents. All pregnant mothers who were admitted one or two days prior to expectant delivery irrespective of mode of termination i.e. Full Term Normal Vaginal Delivery (FTND), instrumental delivery or Lower Segment Caesarean Section (LSCS) were enrolled as participant. It also included mothers of neonates who stayed back in hospital after delivery for phototherapy of their babies.

All expectant mothers admitted for medical or foetal complications for more than two days prior to pregnancy completion or thereafter; parents who reported after third day of hospital discharge or did not report in follow up clinic and parents who did not give consent were excluded. Single parent (only father or mother) who reported to follow up clinic were not excluded from the study.

Study population: A total of 148 participants were eligible for the study out of which 130 (66 mothers and 64 fathers) were enrolled. Mother and father had given their separate estimation and were considered as two different respondents (Figure 1). Cochran's formula was used to calculate the sample size. A sample size of approximately 150 was achieved in a limited population of 1500 (the total number of deliveries in two years in our hospital) with $95 \%$ confidence interval, an estimate of 50\% participants deviating from actual cost and an error of $5-10 \%$.

The parents were asked to come after two days of discharge from hospital in follow up clinic as a part of hospital protocol to monitor the adherence of medical advice and for health education. Parents were interviewed by an intern doctor to answer a predesigned questionnaire verbally. This included details of their education, prior exposure to any other hospital with paid treatment and estimation of approximate expenditure incurred during their hospital stay by the institution on medicinal expenses, procedural and investigation charges, charges for lodging and food, laundry and staff salaries.

Method of Cost Analysis: We restricted to calculation of treatment on medicinal expenses, procedural and investigation charges, food and 
lodging charges and staff salaries (Table 1). Expenses on medicines and consumables were calculated using the last purchase rate by this institution. The prevailing Central Government Health Scheme (CGHS) rates of the year 2014 were applied for other charges and the total cost was calculated. ${ }^{6}$ Staff salaries were calculated per bed per day basis by summing up salaries of all employees involved in patient care at that given day and dividing it per bed.The participants have given their cost estimation in Indian currency (₹). Statistical analysis was done in terms of Indian currency. The conversion rate of 1 United States Dollar (1 USD) = ₹66.77 (as on 1 Mar 2017) was applied for expression of absolute amount of cost estimation, actual expenditure and differences.

Statistical Analysis was done using MINI Tab software version 17. Two sample ' $t$ ' test and ANOVA were used for statistical analysis. Multivariate regression analysis was used to study effect of more than one independent variable on cost estimation. Scatter plot and Box plots were used to study standard deviation. Participant's education status was described quantitatively on Five-Point Likert Scale; (Point-1: Secondary, Point-2: Higher Secondary Level, Point-3: Graduation, Point-4: Post-Graduation, Point-5: Doctorate).

\section{RESULTS}

The average of cost estimated was ₹ 27404 (USD 410.42) vis-a-vis ₹ 18000 (USD 269.58; the average of total cost incurred). Applying two
Table 1. Method of Calculation; rates of procedure (Full term normal delivery/LSCS), per day stay rates as per CGHS rates 2014

\begin{tabular}{|c|c|c|}
\hline $\begin{array}{l}\text { Treatment/ } \\
\text { Technique cost }\end{array}$ & LSCS & FTND \\
\hline $\begin{array}{l}\text { Procedure/ } \\
\text { Technique cost }\end{array}$ & $\begin{array}{r}\text { ₹14050 } \\
(\text { USD 210.42) }\end{array}$ & $\begin{array}{r}\text { ₹8000 } \\
\text { (USD 119.81) }\end{array}$ \\
\hline $\begin{array}{l}\text { Length of } \\
\text { stay(days)@ ₹ } \\
500(\text { USD 7.48) } \\
\text { per day and } \\
\text { includes lodging, } \\
\text { food and laundry }\end{array}$ & $\begin{array}{r}5 \text { days x ₹ } 500 \\
=₹ 2500 \\
(5 \text { days x USD } \\
7.48=\text { USD } \\
37.44)\end{array}$ & $\begin{array}{r}3 \text { days x ₹ } 500 \\
=₹ 1500 \\
(3 \text { days x USD } \\
7.48=\text { USD } \\
22.46)\end{array}$ \\
\hline $\begin{array}{l}\text { Cost of } \\
\text { medicines, other } \\
\text { expendables }\end{array}$ & $\begin{array}{r}\text { ₹ } 2625 \\
(\mathrm{USD} 39.71)\end{array}$ & $\begin{array}{r}\text { ₹2871 } \\
(\text { USD 42.99) }\end{array}$ \\
\hline Investigations & $\begin{array}{r}₹ 165 \\
\text { (USD 2.47) }\end{array}$ & $\begin{array}{r}\text { ₹165 } \\
\text { (USD 2.47) }\end{array}$ \\
\hline $\begin{array}{l}\text { Salaries (per bed } \\
\text { per day) }\end{array}$ & $\begin{array}{r}5 \text { days } x \text { ₹302 } \\
=₹ 1510 \\
(5 \text { days } x \text { USD } \\
4.52=\text { USD } \\
22.61)\end{array}$ & $\begin{array}{r}3 \text { days } x \text { ₹ } 269 \\
=₹ 807 \\
(3 \text { days } x \text { USD } \\
4.02= \\
\text { USD12.08) }\end{array}$ \\
\hline Total & $\begin{array}{r}₹ 20850.00 \\
\text { (USD 312.26) }\end{array}$ & $\begin{array}{r}₹ 13343.00 \\
\text { (USD 199.83) }\end{array}$ \\
\hline
\end{tabular}

sample ' $\mathrm{t}$ ' test on cost estimated and cost incurred, with $95 \%$ confidence interval, the null hypothesis was refuted with a $\mathrm{p}$ value of 0.000 . It revealed poor awareness of participants to estimate the cost of medical expenses. Power Report highlighted that there was a $90 \%$ chance of getting the difference of around ₹5731 (USD 85.83) in estimation. A large

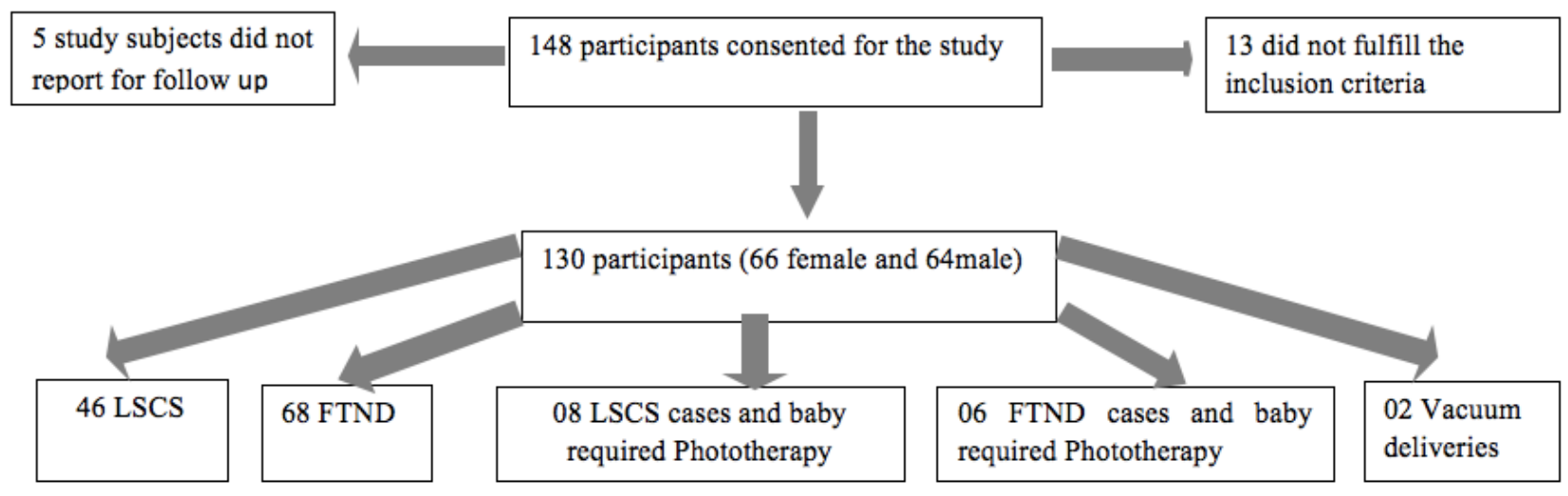

Figure 1. Flow chart of study population 


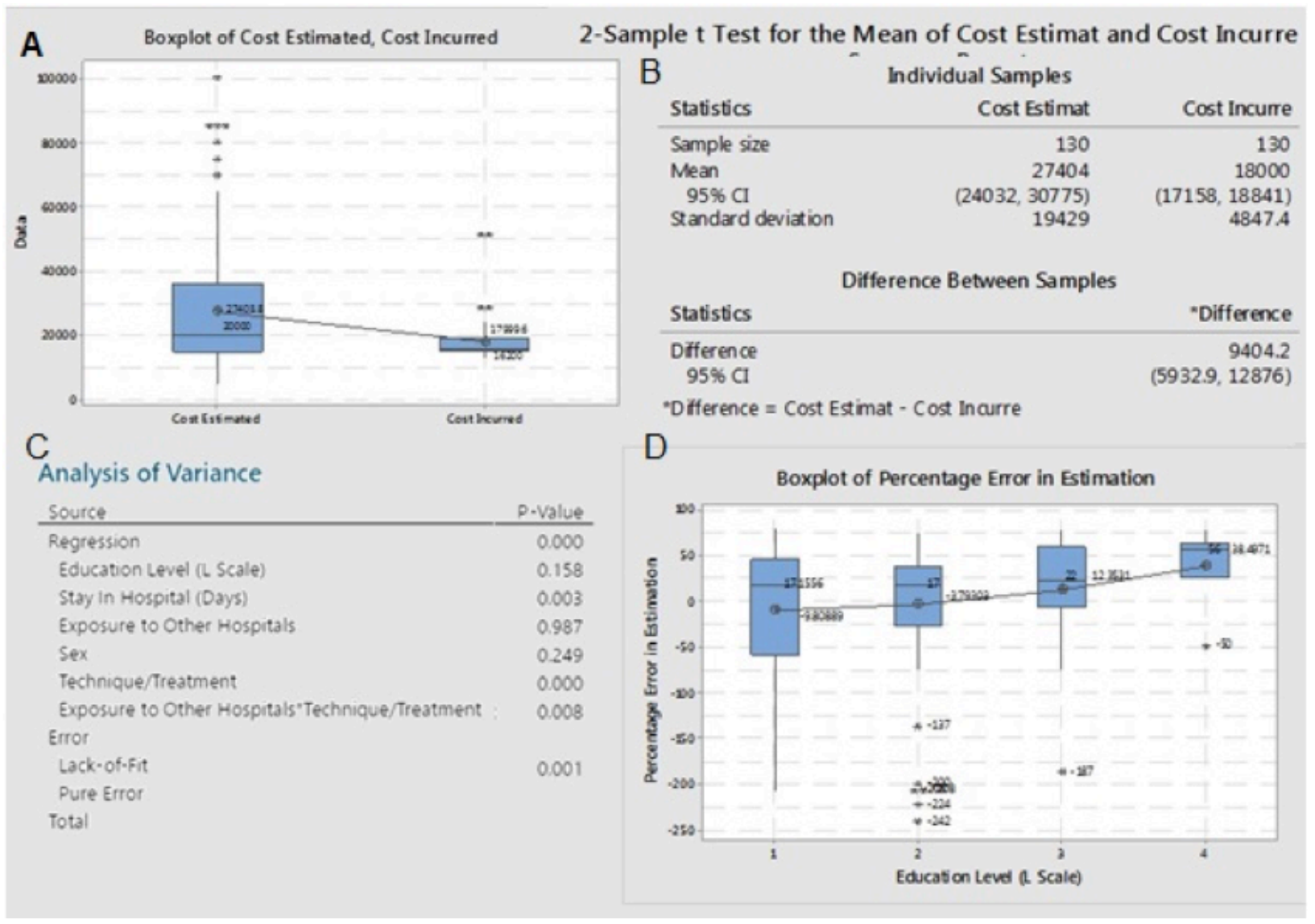

Figure 2. (A) Boxplot of cost estimation \& Percentage Error in estimation with comparison to education level; (B) 2-

Sample $t$ test for the mean of cost estimation; (C) Analysis of Variance; (D) Box plot of percentage error in Cost

scattering of sample responses represented substantial uncertainty in person-to-person

Table 2. Regression Analysis: Cost estimated vs Education, Hospital stay, Exposure, Technique/ Treatment and Multivariate Exposure along with Technique/Treatment

\begin{tabular}{|lcccc|}
\hline Term & Coef & $\begin{array}{c}\text { SE } \\
\text { Coef }\end{array}$ & T value & $\begin{array}{c}\text { p } \\
\text { value }\end{array}$ \\
\hline $\begin{array}{l}\text { Constant } \\
\begin{array}{l}\text { Education level } \\
\text { (L Scale) }\end{array}\end{array}$ & 4596 & 5226 & 0.88 & 0.381 \\
$\begin{array}{l}\text { Stay in hospital } \\
\text { (Days) }\end{array}$ & 1363 & 446 & 3.06 & 0.003 \\
$\begin{array}{l}\text { Exposure to } \\
\text { other hospitals }\end{array}$ & -75 & 4675 & -0.02 & 0.987 \\
$\begin{array}{l}\text { Technique/ } \\
\text { treatment }\end{array}$ & 15421 & 3161 & 4.88 & 0.000 \\
$\begin{array}{l}\text { Exposure to } \\
\text { hospital and } \\
\text { technique }\end{array}$ & 17471 & 6475 & 2.70 & 0.008 \\
Sex & & & & 0.158 \\
\hline
\end{tabular}

estimation; difference of ₹7403 (USD 110.87) between the Mean and Median of cost estimation. There existed a large standard deviation of ₹19429 (USD 290.98) in the estimated costs as compared to ₹4847.40 (USD 72.59) of actual cost (Figure 2). This confers to skewed estimation of the cost by the participants.

The data was also analysed to find out whether the education status of each participant, prior exposure to a paid hospital, gender and length of stay in hospital had any bearing on approximation of the cost of medical expenses. Regression analysis was done for behavioural analysis of patients with respect to estimation of medical expenses. Hypothesis testing was done with $5 \%$ acceptable error. A p-value less than $0.05(\mathrm{p} \leq 0.05)$ was statistically significant indicating strong evidence against null hypothesis, less than $5 \%$ probability that the null is correct. The findings were accepted with $95 \%$ confidence prediction, rejecting the null 

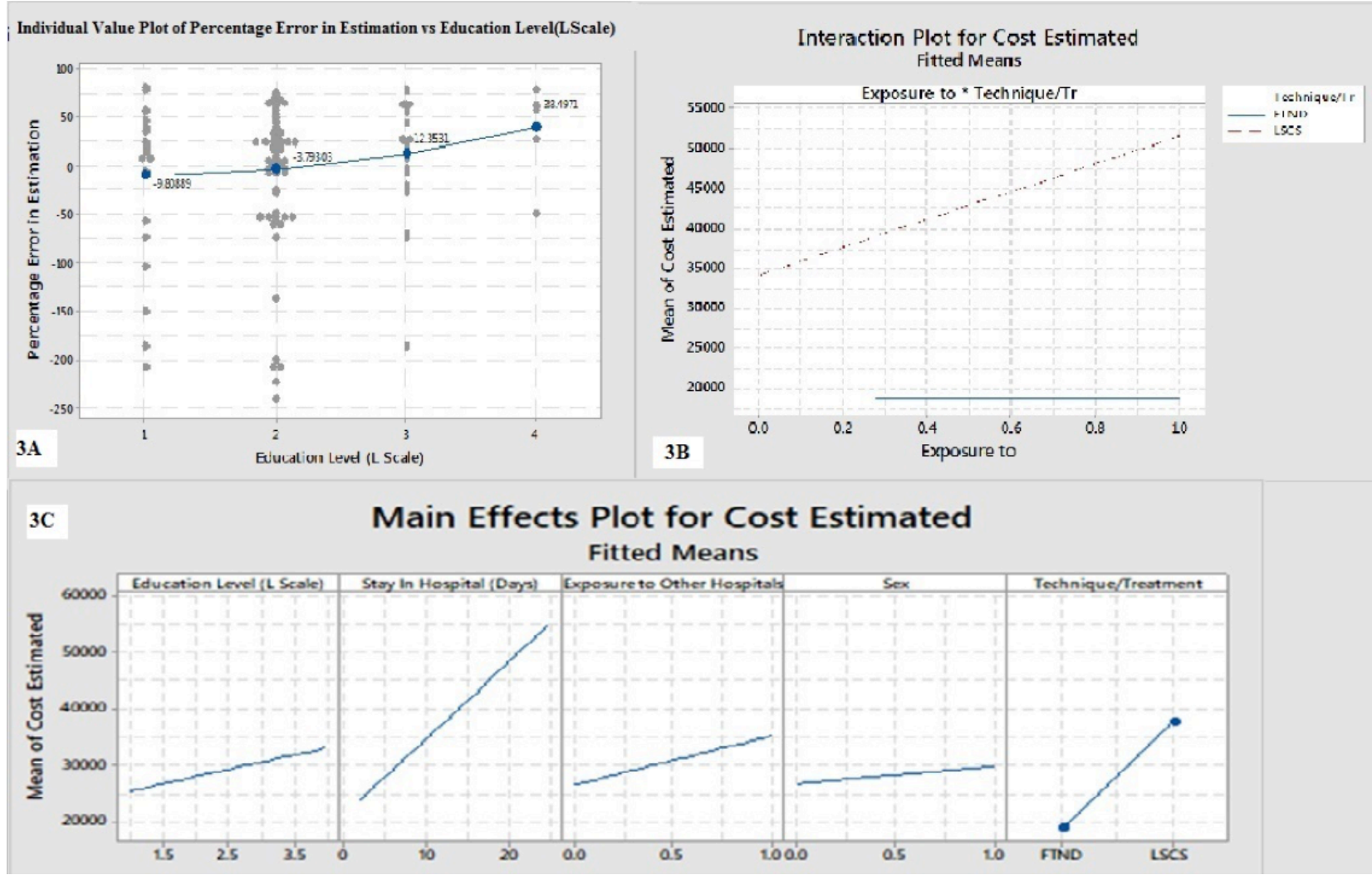

Figure 3. (A) Percentage Error in Estimation versus Education Level on Likert Scale, participants with higher education estimating with less error but overestimating; (B): Interaction Plot of cost estimated with multivariate analysis Exposure to other hospitals along with Technique of delivery (LSCS/FTND); (C): Behaviour analysis using Regression model for cost estimation by participants with respect to education status, length of stay, exposure to other hospitals, technique of delivery.

hypothesis. A significant 'p' value was observed with respect to length of stay $(\mathrm{p}=0.003)$, treatment modality $(p<0.000)$ and the multivariate variable (treatment technique) along with exposure to treatment in paid hospital $(\mathrm{p}=0.008)$. This implied that the cost estimation by the participants varied statistically away from the true cost incurred by the institution when judged with respect to length of stay, treatment modality along with previous exposure to paid hospital (Table 2).

Participants who had better education were expected to predict the incurred cost more accurately. After performing regression analysis, $p$ value $(p=0.158)$ suggested that education level hardly assisted the people in accurate cost estimation. However, when percentage error in estimation (\% Err) was analysed with education status, a statistically significant $p$-value $(p=0.039)$ was obtained. This implied that educated people were overestimating but with less error because of their developed intellectual characteristics (Figure 4A). A statistically significant relation $(\mathrm{p}=0.003)$ was found for total expenditure estimation and length of stay in hospital (Table 2). Participants estimated the expenditure more skewed as the length of stay increased. However, \%Err when plotted against stay in hospital did not reveal much significant relation; the scatter of estimated values around the mean was not significant. A skewed estimation was obtained from the participants if the stay in hospital was four or more days.

Inferential statistics revealed that prior exposure to hospital with paid services did not assist the people in cost estimation from government hospital. The two-way interaction of exposure and the delivery technique together had significant association with the estimation of expenses $(p=0.008)$. In LSCS (Lower segment Caesarean Section) technique, those with less exposure had underestimated, while those with more exposure overestimated the 
treatment costs such that, more the exposure, higher the estimated cost. This was not true for FTND cases (Figure 3B). Treatment modality (LSCS/ FTND), when studied with cost estimation produced a significant correlation $(\mathrm{p}=0.001)$.

Participants estimated more cost for LSCS than for FTND and that \%Err during cost estimation was more for LSCS than FTND. The expenditure for LSCS was overestimated by the participants. The scatter of values around the mean was much more, causing a significant \% Err. A likely explanation is that participants who were exposed were influenced from treatment costs at private hospitals which work on package basis.

The two-way interaction of prior exposure to hospital along with length of stay erupted statistically significant (Figure 3C). The \%Err in estimation was least, when duration of stay was only one to three days, irrespective of prior exposure to hospitals. The \%Err increased up to $50 \%$ or more in both exposed and non-exposed groups with increase in hospital stay of 4 days and more.

\section{DISCUSSION}

The improvement in health care has come at a high financial cost. ${ }^{7,8}$ In developing countries factors like limited health care resources, widespread poverty and lack of medical insurance are major deterrent to free treatment. ${ }^{9}$ A study by Gandhi $R$ et al. and Gijs I van Boxel on health costs awareness revealed that physicians and patients had meagre knowledge of the running cost of medical expenses. ${ }^{10,11}$ Our study is similar to the study by Rinku Sen Gupta Dhar et al. except that in our study estimates were taken two days after discharge to avoid recall bias. ${ }^{12}$ The study brings forth the fact that the study clientele had no idea of the health expenditure. Longer the stay in hospital, the heftier the cost and more skewed estimation. Education did not change the estimate of expenditure; the more educated overestimated but with less error. This might be due to the misconceptions about expenses in government hospitals particularly prevailing in the educated fraternity. On the contrary to our study, Leon Feinstein and Claire Higgins promulgated the positive effects of education for patient awareness about health and health related behaviour. ${ }^{13,14}$

Participants of this study underestimated while estimating the cost for the stay of one to three days but overestimated the cost with less error, for the stay period from four to 20 days. This might be because of too discrete estimation of cost by the participant, when considering this factor of stay in hospital.

A lot of work has been published to assess patient's awareness of health issues and health costs, as various communication modules on health budget have a sturdy impact on the health care system. ${ }^{10,11,15,16}$ Prior exposure to paid medical facilities did not influence estimation of medical cost in a government sponsored setup which can be hypothesised to unawareness about government facilities and aids provided by the government.

However, prior medical exposure did influence the estimation of cost in relation to deliveries via LSCS. Those who were exposed and had LSCS actually overestimated the medical cost. Such a trend might be because of exorbitant and varied rates of LSCS in private and corporate hospitals. This was substantiated by a survey of package rates for LSCS and FTND in five local private hospitals (Three nursing homes and two corporate multispecialty hospitals). The average LSCS package of five days was ₹ 22000 (USD 329.48) with a range of ₹12500 (USD 187.20) to ₹25000 (USD 374.41) and average FTND package of three days was ₹ 12054 (USD 180.53) with a range of ₹6500 (USD 97.34) to ₹17500 (USD 262.09) were levied on patients. This included cost of procedure, medications, hospital stay, food and laundry services.

This study has some methodological limitations. As our study is a pilot study and is not representative study of the whole population, a population based study would still be required. The index study has a disparate number of participants in different subgroups. It was enviable to have equal number of participants in all subgroup for better statistical analysis of secondary outcome. Micro costing method of expenditure calculation would have been more accurate while estimating the expenditure. ${ }^{17}$ 
There may be a wide variation in actual expenditure per bed and accurate estimation may not be possible by patients or their attendants (parents). To keep brevity and discreetness of study, other charges (fixed costs) were not included. CGHS rates were taken for cost estimation which was last revised in the year 2014.

\section{CONCLUSIONS}

The beneficiary clientele were not aware about the government expenses for their treatment. The factors that contribute to wide variation in cost estimation by participants were dependent on length of stay and method of treatment/technique but were independent of prior exposure to paid hospital and education status. Generally, patients tend to over-estimate the costs incurred on LSCS/ Normal Delivery which may be a consequence of high out of pocket expenditure prevailing in the community. Making people aware of costs by actual package rates for these procedures might be a simple disruptive intervention to create awareness of actual cost. It is also recommended to inform the client about the fixed charges which are borne by the government per bed per day. This may act as a buffer to reduce the prevalent patient dissatisfaction to a greater extent.

\section{REFERENCES}

1. Shankar P, Pankaj B, Andrew DP, Atul S, Gursimer B, Vishal Kumar, et al. The Cost of Universal Health Care in India: A Model Based Estimate. PLoS One. 2012;7: 30362. DOI: https://doi.org/10.1371/journal.pone.0030362.

2. Jahanbakhsh P, Babak M, Amir MH, Farahnaz BZ, Hojjat D. Survey Management of Residents' Awareness of the Cost of Hospital Para clinical Measures. Biomed Pharmacol J. 2014;7:645-52. DOI: https://doi.org/10.13005/bpj/ 536.

3. Alexander GC, Casalino LP, Tseng CW, McFadden D, Meltzer DO. Barriers to Patient-physician Communication About Out-of-pocket Costs. J Gen Intern Med. 2004;19:856-60. DOI: 10.1111/j.1525-1497.2004.30249.x.

4. Chatterjee S, Levin C, Laxminarayan R. Unit cost of medical services at different hospitals in India. PLoS One. 2013;8:69728. DOI: https://doi.org/10.1371/journal.pone.0069728.

5. Prinja S, Manchanda N, Mohan P, Gupta G, Sethy G, Sen A, et al. Cost of neonatal intensive care delivered through district level public hospitals in India. Indian Pediatr. 2013;50:839-46. DOI: 10.1007/s13312-013-0234-6.

6. Gconnect. CGHS package rates for treatment in CGHS empanelled private hospitals. Available at: http:// www.gconnect.in/orders-in-brief/cghs/cghs-package-rates-for-treatment-in-cghs-empanelled-private-hospitals.html. Accessed on 11 January 2018.

7. Narang A, Kiran PSS, Kumar P. Cost of neonatal intensive care in a tertiary care center. Indian Pediatr. 2005; 42:989-97. PMID: 16269829.

8. Akman I, Cebeci D, Ozek E. Effects of perinatal factors on the duration and cost of hospitalisation for preterm infants in a neonatal intensive care unit in Istanbul. Turk J Med Sci. 2002;32:159-63.

9. Moazam F, Lakhani M. Ethical dilemmas of health care in the developing nations. J Pediatr Surg. 1990;25:438-41. DOI: 10.1016/0022-3468(90)90389-q.

10. Gandhi R, Stiell I, Forster A, Worthington J, Ziss M, Kitts J B, et al. Evaluating physician awareness of common health care costs in the emergency department. CJEM. 2018;20:539-49. DOI: 10.1017/cem.2017.43.

11. Gijs IB, Bernard HD, Elizabeth JB, Rodney G, Paul G, Shaun A. Patients' and health-care professionals' awareness of cost: A multicentre survey. Br J Hosp Med. 2016;77:42-5. DOI: https://doi.org/10.12968/hmed.2016.77.1.42.

12. Rinku SGD, Jitender N, Swati S, Bhargava VL, Aarti S, Abhishek B. Direct cost of maternity-care services in South Delhi: A community survey. J Health Popul Nutr. 2009;27:368-78. DOI: 10.3329/jhpn.v27i3.3379.

13. Claudia MD, Rachel R, Paola Z. Cost estimate of hospital stays for premature newborns in a public tertiary hospital in Brazil. Clinics (Sao Paulo). 2011;66:1773-7. DOI: https://doi.org/10.1590/S1807-59322011001000016. 
14. Institute of Public Health in Ireland. Health Impacts of Education: a review. Claire H, Teresa L, Owen M. The Institute of Public Health in Ireland, 5th Floor, Forestview, Bishop's Square, Purdy's Lane, Redmond's Hill, Belfast, Dublin, 2 BT8 7ZX, Ireland. 2008; ISBN 978-0-9559598-1-3.

15. Mohammed SA, Saad AA. Patients' Knowledge and Attitudes towards Health Education: Implications for Primary Health Care Services in Saudi Arabia. J Family Community Med. 2009;16(1):27-32. PMID: 23012186

16. Hardee JT, Platt FW, Kasper IK. Discussing Health Care Costs with Patients: An Opportunity for Empathic Communication. J Gen Intern Med. 2005;20:666-9. DOI: https://doi.org/10.1111/j.1525-1497.2005.0125.x.

17. Kannan V, Jeeva SM, Ashok D, Anand K, Vinod K Paul. A micro-costing model of neonatal intensive care from a tertiary indian unit: Feasibility and Implications for Insurance. Indian Pediatr. 2014;51:215-17. DOI: 10. 1007/ s13312-014-0376-1. 